\title{
Diurnal variation of atmospheric Maxwell current over the low-latitude continental station, Tirunelveli, India $\left(8.7^{\circ} \mathrm{N}, 77.8^{\circ} \mathrm{E}\right)$
}

\author{
C. Panneerselvam, K. U. Nair, C. Selvaraj, K. Jeeva, C. P. Anil Kumar, and S. Gurubaran
}

Equatorial Geophysical Research Laboratory, Indian Institute of Geomagnetism, Krishnapuram, Tirunelveli 627 011, India

(Received September 1, 2006; Revised January 5, 2007; Accepted February 21, 2007; Online published June 8, 2007)

\begin{abstract}
Observations of atmospheric Maxwell current from the low-latitude continental station, Tirunelveli $\left(8.7^{\circ} \mathrm{N}\right.$, $77.8^{\circ} \mathrm{E}$ ), over a period of 8 years are presented in this study. The horizontal long-wire antenna is used as a sensor for picking up charges from the atmosphere. The objectives of the present work have been to understand the antenna system in response to different meteorological conditions and on fairweather days. We define a fairweather day as a day when there is no snowfall/rainfall at the measuring site, when there are high clouds less than 3 octas throughout the day, and when the wind speed is less than $10 \mathrm{~m} \mathrm{~s}^{-1}$. A sunrise effect is observed in the measured Maxwell current during fairweather days in all seasons. The measured current exhibits an increase that commences about $30 \mathrm{~min}$ before sunrise and lasts for nearly $1.5 \mathrm{~h}$. The sunrise effect is found to be inhibited on days when there is pre-dawn convection and during the presence of rain, haze, or cloud cover. Barring the sunrise effect, the rest of the variations on fairweather day appear to follow a trend typical of the Carnegie curve. On clear cloudless conditions, reasonably good data are obtained during equinox and winter months but not in summer when strong winds associated with the onset of the southwest monsoon make the measurement of Maxwell current difficult and limited data are available.
\end{abstract}

Key words: Air-earth current, global electric circuit, sunrise effect, atmospheric electric field.

\section{Introduction}

Continuous measurements of atmospheric electrical parameters, namely, the vertical electric field, the conductivity, and the air-Earth current, that characterize the global electric circuit (GEC) are considered useful in any study with the aim of understanding fully the electrical environment of the Earth. Further, since the global circuit links the lower troposphere, the ionosphere, and the magnetosphere, the measurements of atmospheric electrical parameters will be useful in any integrated approach that involves all these regions (Bering, 1995; Rycroft et al., 2000). Longterm measurements from various sites would be considered useful for addressing some of the problems associated with global change.

Many attempts have been made in the past to confirm the global circuit concept first hypothesized by C. T. R. Wilson by identifying global signatures in measured atmospheric electrical parameters (Adlerman and Williams, 1996). The measurement sites need to be free of atmospheric aerosols and convective activity that otherwise would obscure the weak signatures representing global thunderstorm activity (Israel, 1970, 1973). Adlerman and Williams (1996) used data on air-Earth current density from Mauna Loa in Hawaii, a site free of pollution and which remains above the inversion layer most of the time. Ruling out earlier measurements from different stations as possibly due to local processes, Adlerman and Williams (1996) were able to de-

Copyright (c) The Society of Geomagnetism and Earth, Planetary and Space Sciences (SGEPSS); The Seismological Society of Japan; The Volcanological Society of Japan; The Geodetic Society of Japan; The Japanese Society for Planetary Sciences; TERRAPUB. tect the evening peak (at around 1900 UT) in the UT variation of the measured current density over Mauna Loa Observatory.

Apart from the global UT variation, land stations also exhibit certain local time variations, the most pronounced of which is associated with the sunrise effect (Marshall et al., 1999; Marcz et al., 1997). It is believed that the pre-dawn layer of positive charges close to the surface (the electrode effect) gets lifted up in the presence of upward convection generated by surface solar heating (Marshall et al., 1999), causing significant changes in the measured electrical parameters near the surface. Muir $(1975,1977)$ made an attempt to explain this feature on the basis of a hypothesis that involved a charge separation within the electrosphere due to the dynamo motion associated with atmospheric tides. He suggested that this mechanism would be most effective at the geomagnetic equator.

In the present work, vertical Maxwell current measurements are made as part of the ongoing GEC study from a low-latitude site near Tirunelveli $\left(8.7^{\circ} \mathrm{N}, 77.8^{\circ} \mathrm{E}\right)$, close to the southern tip of the Indian peninsula. The objectives of the study are to examine the possibility of detecting global signatures in the tropical Indian zone and evaluate the contributions of local processes to the variabilities of atmospheric electrical parameters measured during the course of the work. The environmental and meteorological conditions at the measuring site and the orography relevant to the atmospheric electricity measurements reported in the present work are discussed below.

The experiment site ( $\sim 30 \mathrm{~m}$ above mean sea level) is more than $12 \mathrm{~km}$ southeast of the twin towns of Tirunelveli 
Table 1. Y-Data available, N-No data. No of fair weather days yearwise: 1997-21, 1998-41, 1999-58, 2000-63, 2001-93, 2002-92, 2003-101, 2004-0, 2005-118. Total No of fair weather days: 587.

\begin{tabular}{lllllllllllll}
\hline YEAR & JAN & FEB & MAR & APR & MAY & JUN & JUL & AUG & SEP & OCT & NOV & DEC \\
\hline 1996 & $\mathrm{~N}$ & $\mathrm{~N}$ & $\mathrm{~N}$ & $\mathrm{~N}$ & $\mathrm{~N}$ & $\mathrm{Y}$ & $\mathrm{Y}$ & $\mathrm{Y}$ & $\mathrm{Y}$ & $\mathrm{Y}(6)$ & $\mathrm{Y}$ & $\mathrm{Y}$ \\
1997 & $\mathrm{Y}(6)$ & $\mathrm{Y}(0)$ & $\mathrm{Y}(13)$ & $\mathrm{Y}(2)$ & $\mathrm{Y}(0)$ & $\mathrm{Y}(0)$ & $\mathrm{Y}(0)$ & $\mathrm{Y}(0)$ & $\mathrm{Y}$ & $\mathrm{N}$ & $\mathrm{N}$ & $\mathrm{N}$ \\
1998 & $\mathrm{~N}$ & $\mathrm{~N}$ & $\mathrm{~N}$ & $\mathrm{~N}$ & $\mathrm{~N}$ & $\mathrm{Y}(0)$ & $\mathrm{Y}(14)$ & $\mathrm{Y}(0)$ & $\mathrm{Y}(0)$ & $\mathrm{Y}(0)$ & $\mathrm{Y}(15)$ & $\mathrm{Y}(12)$ \\
1999 & $\mathrm{Y}(9)$ & $\mathrm{Y}(7)$ & $\mathrm{Y}(10)$ & $\mathrm{Y}(0)$ & $\mathrm{N}$ & $\mathrm{N}$ & $\mathrm{Y}(4)$ & $\mathrm{N}$ & $\mathrm{Y}$ & $\mathrm{Y}$ & $\mathrm{Y}(11)$ & $\mathrm{Y}(17)$ \\
2000 & $\mathrm{Y}(12)$ & $\mathrm{Y}(13)$ & $\mathrm{Y}(5)$ & $\mathrm{Y}(0)$ & $\mathrm{Y}(0)$ & $\mathrm{Y}(12)$ & $\mathrm{Y}(3)$ & $\mathrm{Y}(0)$ & $\mathrm{Y}(0)$ & $\mathrm{Y}(2)$ & $\mathrm{Y}(10)$ & $\mathrm{Y}(6)$ \\
2001 & $\mathrm{Y}(11)$ & $\mathrm{Y}(18)$ & $\mathrm{Y}(19)$ & $\mathrm{N}$ & $\mathrm{N}$ & $\mathrm{N}$ & $\mathrm{Y}(12)$ & $\mathrm{Y}(17)$ & $\mathrm{Y}(4)$ & $\mathrm{N}$ & $\mathrm{Y}(6)$ & $\mathrm{Y}(6)$ \\
2002 & $\mathrm{Y}(21)$ & $\mathrm{Y}(2)$ & $\mathrm{Y}(7)$ & $\mathrm{Y}(5)$ & $\mathrm{Y}(0)$ & $\mathrm{Y}(8)$ & $\mathrm{Y}(16)$ & $\mathrm{Y}(12)$ & $\mathrm{Y}(7)$ & $\mathrm{Y}(6)$ & $\mathrm{Y}(8)$ & $\mathrm{N}$ \\
2003 & $\mathrm{Y}(5)$ & $\mathrm{Y}(11)$ & $\mathrm{Y}(15)$ & $\mathrm{Y}(16)$ & $\mathrm{Y}(8)$ & $\mathrm{Y}(5)$ & $\mathrm{Y}(12)$ & $\mathrm{Y}(10)$ & $\mathrm{Y}(19)$ & $\mathrm{N}$ & $\mathrm{N}$ & $\mathrm{N}$ \\
2004 & $\mathrm{~N}$ & $\mathrm{~N}$ & $\mathrm{Y}$ & $\mathrm{Y}$ & $\mathrm{Y}$ & $\mathrm{N}$ & $\mathrm{N}$ & $\mathrm{N}$ & $\mathrm{N}$ & $\mathrm{N}$ & $\mathrm{N}$ & $\mathrm{N}$ \\
2005 & $\mathrm{Y}(19)$ & $\mathrm{Y}(12)$ & $\mathrm{Y}(17)$ & $\mathrm{N}(0)$ & $\mathrm{Y}(18)$ & $\mathrm{Y}(20)$ & $\mathrm{Y}(11)$ & $\mathrm{Y}(4)$ & $\mathrm{Y}(7)$ & $\mathrm{Y}(5)$ & $\mathrm{Y}(0)$ & $\mathrm{Y}(5)$ \\
\hline
\end{tabular}

and Palayamkottai. The nearest cement factory is located at a distance of about $15 \mathrm{~km}$ to the northwest. It may be noted that moderate-to-intense southwesterly winds blow during one half (April-September) of the year over the region of observation, while moderate north-easterlies blow during the other half (October-March) of the year. The site is about $35 \mathrm{~km}$ from the Bay of Bengal, and the nearest hills of Western Ghats are at distances of approximately $45 \mathrm{~km}$ to the west and the southwest. Further, the crustal part of the Earth underneath the site is fixed on solid rocks, and hence does not support dense vegetation.

The experiment site receives rainfall normally in the months of October and November during the northeast monsoon, while occasional rains occur during the summer when the southwest monsoon prevails in the Indian subcontinent. Scanty rainfall over most of the year in this region permits a large number of atmospheric electricity measurements to be made. Being in the tropics, this region is under the influence of convection that is expected to be severe around summer period (April-June).

\section{Experimental Technique}

There are a variety of experimental techniques discussed in the literature for the measurements of atmospheric electrical parameters, namely, the electric field, conductivity, and current. Widely used ground-based sensors for the measurement of air-Earth current are the Wilson plate (Israel, 1973), the horizontal long-wire antenna (Kasemir, 1955; Ruhnke, 1969) and the spherical shell in the form of two hollow hemispheres (Burke and Few, 1978). The long-wire antenna allows for the suppression of local disturbances by averaging the vertical current over a large area (Ruhnke, 1969). The present work makes use of this technique for the measurements of the air-Earth current from the lowlatitude site. The horizontal long-wire antenna, if placed in the atmosphere, will closely follow the electrical current variations of the atmosphere after the initial net charge on the antenna leaks off. When the antenna is shorted to the ground through a resistor, it will pick up a certain amount of current proportional to the Maxwell current density. For the measurement of atmospheric current with the antenna, the inner resistance (feedback resistance) of a current meter is always smaller than the columnar resistance of the electric source measured. The time constant (RC) of the electric circuit is $1 \mathrm{~s}$. In our experiment, we use a long-wire an- tenna of $144 \mathrm{~m}$ in length and $3 \mathrm{~mm}$ in diameter that would collect incoming charges from the atmosphere. The sensor is supported $1 \mathrm{~m}$ above the ground by means of masts that are electrically separated by Teflon rods (Panneerselvam et al., 2003). It is connected to an electrometer (AD 549) that has high-input impedance on the order of $10^{9} \Omega$ and permits extremely low-input bias current $\left(10^{14} \mathrm{~A}\right)$. The electrometer converts the current into voltage and measures the current from $\mathrm{pA}$ to $2 \mathrm{nA}$ with the high feedback resistance $\left(5 \times 10^{9} \Omega\right)$. A unity gain operational amplifier (LM308) is connected to the electrometer output signal. The output signals are filtered by a low-pass filter with a cut-off frequency of $1 \mathrm{~s}(3 \mathrm{~dB})$ at the input of ADC, which is $100 \mathrm{~m}$ away from the preamplifier. The filtered signal is fed to the 12-bit ADC (AD574) with 2.44-mV resolution which is mounted in the personal computer (PC). The PC records the signal at a sampling interval of $1 \mathrm{~s}$. An hourly averaging of the data samples further eliminates any short-period variations in the measured current density. The effective area of the present experimental setup is $158.12 \mathrm{~m}^{2}$, calculated from the formula $(S=h c / \epsilon$ ), where $\epsilon$ is the dielectric constant of air, $c$ is the capacity of the antenna, and $h$ is the height of the antenna above ground. The total current density can be estimated by dividing the measured current by the effective area of the antenna (Tammet et al., 1996).

The Maxwell current density includes the following components. $\mathrm{J}_{\mathrm{c}}$ is the conduction current and corona current. $\mathrm{J}_{\mathrm{cv}}$ is the convection current density and is due to the atmospheric free charges displaced by the large-scale air movements. $J_{d}$ is the density of the diffusion current ( $=$ displacement current) due to the movement of charged particles from a region of high ion concentration to one of lower concentration; it is calculated by considering the variation of the electric field with respect to time. $\mathrm{J}_{1}$ is the density of the current created by the rapid transfer of charges during flash. $\mathrm{J}_{\mathrm{p}}$ is the density of the precipitation current during rain. Among these components the convection current diffusion is usually negligible close to surface. The contributions from the precipitation and the lightning currents are negligible in the present work since the data sets selected essentially represent fairweather periods. Assuming the sharp edges provided by plants and trees allow for point-discharge currents, our experiment site should minimize such effects since it is located on barren vegetation-free land. Further, the sensor complex is periodically cleaned, thus preventing 
(a)

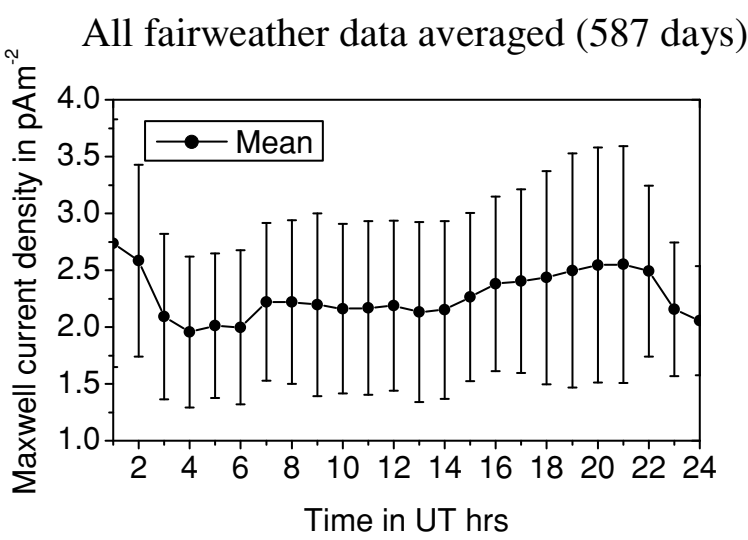

(b)

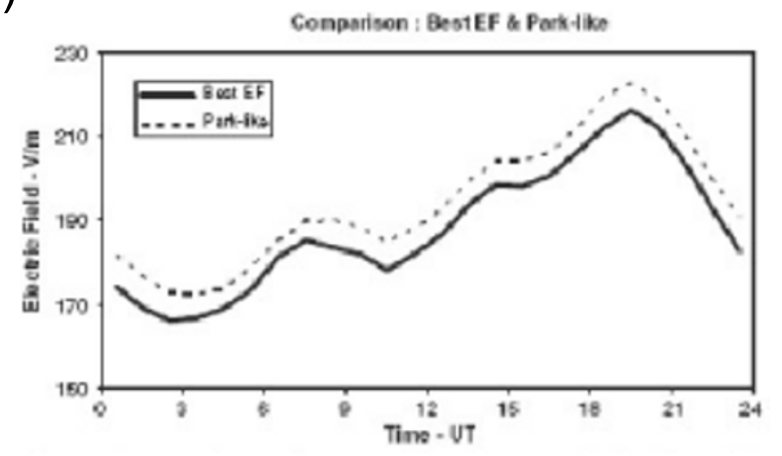

Fig. 1. (a) The overall average diurnal variation of the Maxwell current during the period 1997-2005. (b) Average diurnal curves of vertical electric field, Vostok (from Burns et al., 2006).

the growth of grass or vegetation. When the electric field approaches zero, all the current density components linked to it are also negligible, especially the corona current. We have taken hourly averages for the analysis and, hence, the displacement current is negligible. The measured Maxwell current has only a conduction current. The data obtained on the ground, solely from the variation of the electric field, are sufficient for the determination of the Maxwell current without taking the other currents into account (Despiau and Houngninou, 1996)

\section{Selection of Experiment Data}

Measurements of atmospheric electric currents have been carried out at Tirunelveli since March 1995. After initial test runs for more than 1 year, the Maxwell current data have been available for analysis since May 1996. The selection of the fairweather days has been made using the standard procedure adopted in the past (Reiter, 1985). In the present study, two types of data sets are selected for analysis. For one set, days during which fairweather conditions prevailed are considered, and the hourly averages of Maxwell current are computed to yield the diurnal variation. The data were examined for features corresponding to the UT variation. If thunderstorm activity were responsible for the generation of global electrical circuit and its variation with time, one would expect a maximum in the measured electrical parameters near 19:00 UT and a mini- mum near 03:00 UT (Parkinson and Torreson, 1931; Whipple and Scrase, 1936). The other type of data set included days on which disturbed local weather conditions, other than fair weather, occurred; these include (1) thunderstorm and showers and (2) fog conditions.

\section{Observations}

The hourly averaging procedure is most suited for identification of the signatures of the global electric circuit. Since the charge generated by a thunderstorm somewhere on the globe is distributed in the equalizing layer (ionosphere) within 10-15 min, mean values of at least $30 \mathrm{~min}$ in duration would be required if the global thunderstorm activity is to be adequately represented (Reiter, 1992). Onehour averages are considered in the present work for examining the diurnal variation in the measured currents. For the nonfairweather conditions mentioned above, 1-min averages are examined.

\subsection{Diurnal variation at Tirunelveli, India}

We have explored the possibility of identifying the signature of the DC global circuit in our Maxwell current data. For this purpose only, the fairweather days each month are considered and the diurnal variations are closely examined. The number of fairweather days for each month during the years 1996-2005 is provided in Table 1. A total of 587 fairweather days were observed during this period. The overall average diurnal variation of the Maxwell current for the period 1997-2005 is shown in Fig. 1(a). The error bars indicate the standard deviation representing the variation in the observed current density. The diurnal variation has a minimum at about 04:00 UT and two maximums, one at 01:00 UT and the second at approximately 20:00 UT. The first maximum is the local sunrise effect, and the second maximum in the pre-midnight (Local Time $=\mathrm{UT}+5.30 \mathrm{~h})$ hours is possibly associated with the global peak in thunderstorm activity. The raw data sets reveal that the current density begins to rise at local sunrise at approximately 01:00 UT, and the normal daytime value is reached in less than $2 \mathrm{~h}$ after the sunrise. This feature is often referred to as the 'sunrise effect' (Muir, 1975; Panneerselvam et al., 2003). It is believed to be associated with the generation of a pre-dawn layer of positive charges close to the surface (the electrode effect) and the subsequent uplifting of the layer through upward convection generated by surface solar heating (Marshall et al., 1999). This effect is not detected on mornings when there is rain, haze, or dense cloudiness. The maximum that occurred in the premidnight hours for each fairweather day might be associated with the global thunderstorm activity. Excluding the sunrise enhancement, the diurnal variation of the measured Maxwell current at Tirunelveli resembles the Carnegie curve discussed often in the literature (Roble, 1985). The measured Maxwell current density compared with the past reports of electric field measured at Vostok, Antarctica is shown in Fig. 1(b).

\subsection{Diurnal variation at an Indian Antarctic station}

Atmospheric electricity experiments are carried out from the Indian Antarctic station, Maitri $\left(70.8^{\circ} \mathrm{S}, 11.8^{\circ} \mathrm{E}\right)$, in the Antarctica. An experiment setup that involves a long-wire antenna of length $41.5 \mathrm{~m}$ measuring the current at a height of $1.5 \mathrm{~m}$ was commissioned at Maitri during the 19th Indian 
(a)

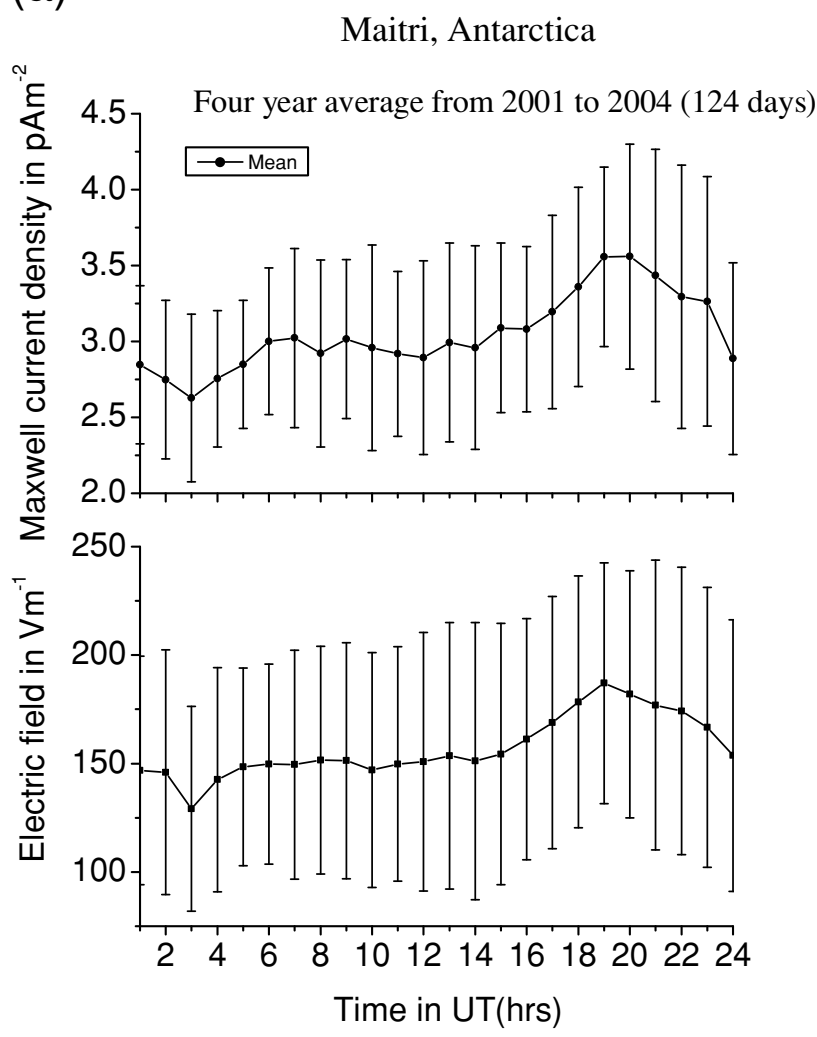

(b)

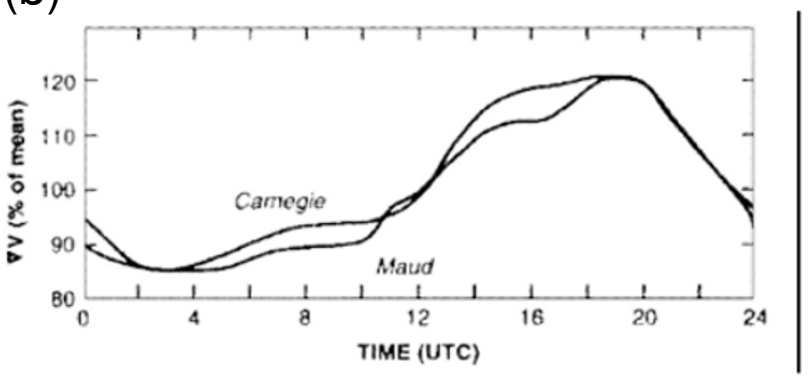

Fig. 2. (a) Diurnal variation of the electric field and Maxwell current during the period 2001-2004. (b) Diurnal variations of the fairweather potential gradient expressed as a percentage of the mean potential gradient at the ocean surface from measurements made aboard the sailing research ships Carnegie and Maud, versus Universal Time. This variation in potential gradient is often referred to as the Carnegie curve (from Whipple and Scrase, 1936).

Expedition to Antarctica. An electric field mill is used for the measurement of atmospheric electric potential (Deshpande and Kamra, 2001). The Antarctic station has been chosen as our instrument site for several reasons. Most importantly, the station is situated on the Antarctica plateau, a region where the atmosphere is more suited for making measurements of GEC (Park, 1976; Cobb, 1977). There is almost no thunderstorm activity in Antarctica; therefore, atmospheric currents at these regions can be regarded as a closure segment of the global electric circuit. The global circuit involves lower atmosphere generators and upper atmosphere generators, the latter being significant over the polar caps. The Antarctic plateau supports a desert-like climate with clear skies and very low atmospheric aerosol content. In summer, the prevailing winds are light, flowing in a nearly constant direction, and the atmosphere is relatively free of turbulent and convective motions (Byrne et al., 1993). Thus, the wind-induced conductivity fluctuations that contribute to meteorological noise in the measured atmospheric electric parameters are minimized when experiments are conducted in the Antarctic. Atmospheric electrical measurements made in Antarctica are useful in investigating large-scale electrical processes unique at high latitudes (Byrne et al., 1991). The downward air-Earth current being delivered to the surface of the Antarctica plateau is larger than the global average owing to its high latitude. Therefore, because of its orography, the Antarctica plateau is strongly coupled to the GEC. The ice surface is flat and void of obstructions, and the electrical conductivity of the surface ice is several orders of magnitude higher than that of the air (Cobb, 1977). Hence, the surface is essentially an infinite conducting plane at ground potential.

In this paper we report observations of the atmospheric Maxwell current and electric field made at Maitri during fairweather days for the period 2001-2004 Fig. 2(a). The error bar indicates the standard deviation from the mean. The diurnal variation has a single periodic variation with a minimum at 03:00 UT and a maximum at 19:00 UT. The diurnal variation in the measured atmospheric electrical parameters are compared with the familiar "Carnegie curve" in Fig. 2(b). Both the current and electric field variations are similar because the conductivity during fairweather conditions is nearly constant. This variation has been widely observed elsewhere and, according to classical theory, is generally attributed to the variation with time of day of the thunderstorm activity across the globe (Roble, 1985). The data from Antarctica show that the sunrise effect is not present at Maitri station when this feature is observed at the low-latitude continental station, Tirunelveli.

\section{Analysis of Disturbed Weather Conditions \\ 5.1 Thunderstorm and showers}

In this section we have done analysis during the disturbed weather conditions like rain, shower and lightning. July 24, 1998 is considered to be a good example of days in which there was rain and thunderstorm activity. On this day, intense convection led to the development of a thunderstorm during the afternoon. For the period of lightning the variation in the current for this day between 09:30 and 11:30 UT is shown in Fig. 3. The thunderstorm activity with a few visible lightning strokes took place over the measuring site between 10:15 and 10:45 UT. Severe rains persisted between 10:00 and 11:00 UT.

It may be noted in Fig. 3 that at times of lightning strokes the current fluctuated between the extremes. The onset of rainfall is clearly marked by the rapid increase in the current that commenced at approximately 09:45 UT. With the traditional view that lightning brings down negative charges and rain positive charges (Israel, 1973), one would expect a downward or upward current trend depending on the incoming charge polarities. A change in the sign of the measured current clearly indicates the dominance of lightning current around these times and conforms to the traditional view that the fairweather electric field changes its direction during 


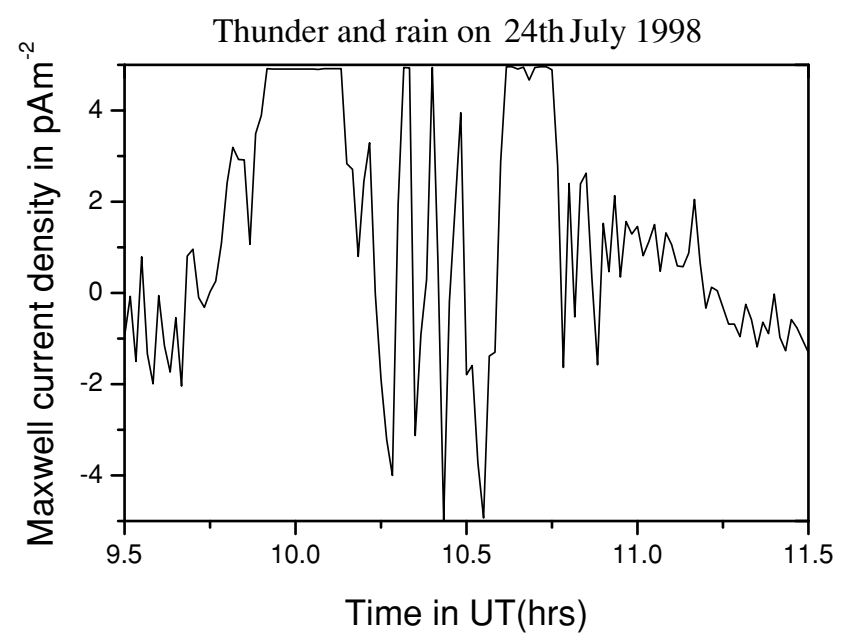

Fig. 3. Maxwell current variation on 24 July 1998 in response to thunderstorm and rain.

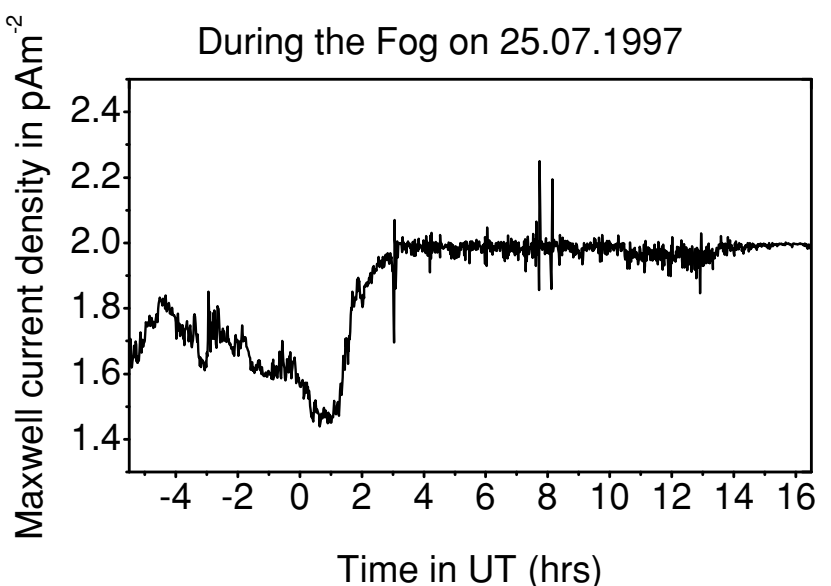

Fig. 4. Maxwell current variation on 24-25 July 1997 in response to fog.

thunderstorm activity. On the other hand, during the course of rain, the condensed water droplets normally forming near the top of the thundercloud are expected to carry positive charges and, hence, on precipitation near the ground they are expected to cause an increase in the measured current density. Despiau and Houngninou (1996) carried out measurements of electric charges of raindrops, electric field, and Maxwell current during intense storms and showers at a tropical location in West Africa. One of the characteristic features of the storms was the presence of predominantly positive hydrometers with charges between 80 and $240 \mathrm{pC}$.

The observed features described above clearly indicate that the horizontal antenna wires do respond to the electrical disturbances occurring in the near-Earth space environment. 5.2 Fog

Fog is one of the factors that influence the Maxwell current variation. The necessity of studying the electrical properties of fog is also dictated by a number of practical problems, such as possible means for the fog forecast and control, influence of aerosol and dust systems to the electric field and current in the atmosphere, and the search for mechanisms of solar-terrestrial relationship (Smirnov, 1992). It has been observed that the conductivity of the atmosphere decreases significantly at the onset time of the fog (Hoppel et al., 1986). An unseasonal rain that occurred over the measuring site on 24 and 25 July 1997 provided an ideal condition for fog development to occur. The variation in the measured current density for this period is depicted in Fig. 4. The fog was centered near the sensor complex at approximately 01:30 UT on 25 July, and then drifted towards the east at about 01:40 UT. During this period, the current level decreased to a minimum between 00:30 and 01:30 UT. This observation agrees with the results reported in earlier works by Dolezalek (1963) and Serbu and Trent (1958). Prospero (1984) showed that before fog visibly forms, the growing droplets capture atmospheric ions, thereby increasing the resistivity of air and leading to a rapid reduction in the current density. When the droplets begin to fall, the thickness of the fog layer decreases and, consequently the columnar resistance of the air decreases. This is expected to cause an increase in the measured current density. The present experiment is thus shown to be consistent with these previous observations.

\section{Discussion}

As mentioned in the Introduction, continuous groundbased measurements of atmospheric electrical parameters are valuable for establishing the regional electrical climate. They are also necessary for understanding what processes control and maintain the global electrical circuit. For this purpose, long-term measurements need to be made under fairweather conditions at sites remotely located from anthropogenic influences. It was believed in the past that sensors located within the planetary boundary layer in a tropical site would essentially measure electrical parameters influenced by boundary layer processes like convection and turbulence. On the other hand, equipment installed on a mountain top above the boundary layer, on a remote island, or on an ocean surface are expected to measure the atmospheric electrical parameter signals associated with the thunderstorm activity, presuming that Wilson's classical hypothesis is true. In this scenario, the measurements of Maxwell current measurements reported herein from a remote tropical location are considered to be important.

Having established the sensitive nature of the long-wire antenna to the changing electrical environment, the diurnal behavior of the measured current at Tirunelveli during fairweather conditions was examined. The prominent features in the diurnal behavior are the sunrise effect and the minimum and the pre-midnight maximum in the Maxwell current. In Fig. 1(a) we have removed the sunrise effect data points for comparing the tropical station Maxwell current, density with the polar station atmospheric electrical parameters. Excluding the local sunrise effect in the measured Maxwell current, the diurnal behavior is remarkably similar with the past reports of electric field measured at Vostok, Antarctica. The Maxwell current data from Tirunelveli do in fact reflect the global changes in the atmospheric electrical parameters, and they are not contaminated by local disturbances. The sunrise effect measured at Pune, another tropical Indian site, using a field mill has been reported in a recent publication (Latha et al., 2003). The morning rise is attributed to a local effect, and the same effect is not ob- 


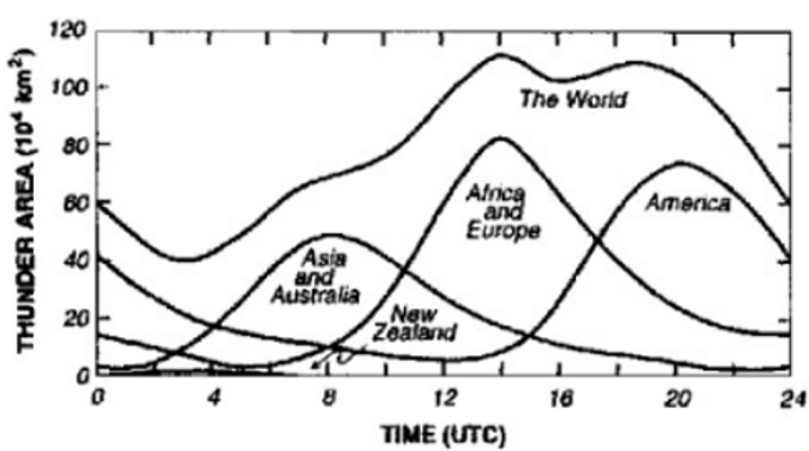

Fig. 5. Diurnal variation of worldwide areas of thunder over land. Individual curves are labeled to indicate the continental regions whose thunderstorm activity is plotted (from Whipple and Scrase, 1936).

served at the high-latitude site, Maitri, the Indian station located in Antarctica. Marshall et al. (1999) have reexamined the sunrise effect using electric field soundings and a network of electric field mills at Kennedy Space Center in Florida. Their results confirm the role played by convection in causing the sunrise enhancement, namely, the lifting of the dense electrode layer that takes place around sunrise when the surface solar heating is activated. The local pre-midnight maximum in the measured Maxwell current occurring at approximately 20:00 UT in the present work is possibly associated with the DC component of the global electric circuit.

The day-to-day variability in the pre-midnight maximum is attributed to the different thunderstorm regions active at different times worldwide, as shown in Fig. 5. The thunderstorm processes over the Malaysian Archipelago and the adjoining maritime continent extending from South Asia across the Philippines, Indonesia, and Borneo into Northern Australia, are active around 1000 UT. The subSaharan African region is active around 16:00 UT, and the Americas-principally, the Amazon basin in South America-are active around 22:00 UT. The other mechanisms that might influence the occurrence of this maximum are the ionospheric wind dynamo process and the solar wind-magnetosphere interaction. Both these processes lead to a large potential drop within the upper atmosphere, thereby contributing to significant changes in the spatial and temporal behavior of the global air-Earth current (Roble, 1985). A detailed study is currently being planned that will enable a more comprehensive study of the processes.

The diurnal variation of atmospheric electric parameter measurements made at Maitri, Antarctica has a single periodic feature with a minimum at 03:00 UT and a maximum at 19:00 UT. Maitri offers an exceptionally good location for monitoring fairweather atmospheric electrical parameters associated with the global electric circuit because it is relatively free from local disturbances, such as chargebearing clouds, man-made atmospheric pollution, among others. Figure 2(a) indicated that the Maxwell current and electric field data from Maitri, Antarctica are in good agreement with earlier measurements made over oceans (Whipple and Scrase, 1936). The diurnal trend in the measured parameters is consistent with the familiar "Carnegie curve" variation. This variation has been widely observed and, according to classical theory, is generally attributed to the variation with time of day of the number of thunderstorms across the globe (Roble, 1985). Part of the day-to day variations may be ascribed to the solar wind/magnetospheric and ionospheric contribution because our station is outside the region of auroral oval during the magnetically quiet times and is encompassed by the auroral oval under magnetically disturbed conditions. According to the modern GEC theory, one also has to include the magnetospheric/ionospheric contributions.

During disturbed weather conditions, such as fog and thunderstorms, variation in the current has been demonstrated. At the onset of precipitation the measured current increases, while during intense rainfall, the measurements reveal saturation at their detectable levels. This behavior has been observed at every occurrence of strong downpours. On the other hand, during individual lightning strokes, the current detected by the long-wire antenna fluctuates between extreme values $( \pm 1 \mathrm{nA})$. It is possible that the sign of the current reverses in response to the reversed polarity of the electric field at such instances. Studying the electrical properties of fog requires the development of modeling with consideration for the microphysics of particle charging and the availability of external sources of ionization and the electric field in the atmosphere (Sorokin, 2001; Anisimov et al., 2003; Mareev and Anisimov, 2003). The fog developed due to radiation cooling of the air in the surface layer; in the morning, the advection of the warmer moist air took place. A characteristic feature of the fog typically causes the current density to decrease (Anisimov et al., 2005). At times of fog development, the current tends to diminish in its magnitude, recovering later as the fog disappears. This feature is explained based on the reasoning that as the fog thickens, the growing droplets reduce the conductivity and, hence, the current flowing to the sensor. As the fog dissipates, the evaporation of water drops leads to a slow recovery of the conductivity, and the current returns to the initial values. Burke and Few (1978) observed a similar fog effect on the air-Earth current density measured at Houston.

\section{Conclusion}

The long-wire antenna employed in the present work has been demonstrated to provide useful data on the Maxwell current from a tropical pollution-free site. The morning sunrise enhancement observed on many fairweather days is a local/regional effect, whereas the pre-midnight maximum in the Maxwell current is attributed to the integrated thunderstorm activity that is expected to peak at these hours. The presence of the DC component of the global electric circuit in these data sets is inferred when comparisons are made with simultaneous observations carried out from the Indian Antarctic station, Maitri. Excluding the morning local sunrise effect, the Maxwell current density at a tropical station is good agreement with the past reports on the diurnal behavior of electric field data at Vostok, Antarctica and the famous Carnegie curve. The diurnal variation of the Maxwell current and electric field at the polar station Maitri resemble the future the Carnegie curve. Future studies will focus on ionospheric/magnetospheric contribution 
to the measured electrical parameters during different geomagnetic conditions at a tropical station and polar station. The long-term operation of various atmospheric electrical sensors in Antarctica will enable a comprehensive study on the processes that control the global electric circuit as well as provide useful information about the influence of ionosphere-magnetosphere interactions occurring in the polar cap region on the global electric circuit.

Acknowledgments. The authors express their gratitude to the Department of Science and Technology (DST), India. This work is also a part of the activities under the DST project 'Coupling of Ionospheric and Lower Atmospheric Components of the Global Electric Circuit'. The logistic support provided by the Department of Ocean Development, India, for conducting experiments at the Indian Antarctic station, Maitri, is gratefully acknowledged.

\section{References}

Adlerman, E. J. and E. R. Williams, Seasonal variation of the global electric circuit, J. Geophys. Res., 101, 29,679-29,688, 1996.

Anisimov, S. V., E. A. Mareev, A. E. Sorokin, N. M. Shikhova, and E. M. Dmitriev, Electrodynamical properties of the fog. Izv., Atmos. Ocean. Phys., 39(1), 341-347, 2003.

Anisimov, S. V., E. A. Mareev, N. M. Shikhova, A. E. Sorokin, and E. M. Dmitriev, On the electro-dynamical characteristics of the fog, J. Atmos. Res., 76, 16-28, 2005.

Bering, E. A., The global circuit: Global thermometer, weather by-product or climate modulator?, Rev. Geophys. Suppl., 845-862, 1995.

Burke, H. K. and A. A. Few, Direct measurements of the atmospheric conduction current, J. Geophys. Res., 83, 3093-3098, 1978.

Burns, G. B., B. A. Tinsley, A. R. Klekociuk, O. A. Troshichev, A. V. Frank-Kamenetsky, M. L. Duldig, E. A. Bering, and J. M. Clem, Antarctic polar plateau vertical electric field variations across heliocentric current sheet crossings, J. Atmos. Terr. Phys., (68), 639-654, 2006.

Byrne, G. J., J. R. Benbrook, and E. A. Bering, Balloon observations of atmospheric electricity above the South pole: vertical electric field, conductivity and conduction current, J. Atmos. Terr. Phys., 53(9), 859$868,1991$.

Byrne, G. J., J. R. Benbrook, E. A. Bering, A. A. Few, G. A. Morris, W. J. Trabucco, and E. W. Paschal, Ground based instrumentation for measurements of atmospheric conduction current and electric field at South pole, J. Geophys. Res., 98, 2611-2618, 1993.

Cobb, W. E., Electrical Process in Atmospheres, edited by H. Dolezalek and R. Reiter, Steinkopff, Darmstadt, 161-167, 1977.

Deshpande, C. G. and A. K. Kamra, Diurnal variations of the atmospheric electric field and conductivity at Maitri, Antarctica, J. Geophys. Res., 106, 14,207-14,218, 2001.

Despiau, S. and E. Houngninou, Raindrop charge, Precipitation and Maxwell currents under tropical storms and showers, J. Geophys. Res., 101, 14,991-14,997, 1996.

Dolezalek, H., The atmospheric electric fog effect, Rev. Geophys., 1, 231$282,1963$.

Hoppel, W. A., R. V. Anderson, and J. C. Willett, Atmospheric electricity in the planetary boundary layer, in The Earth's Electrical Environment, pp. 149-165, Natl. Acad. Press, Washington D.C., 1986.

Israel, H., Atmospheric Electricity, vol. I, Fundamentals, Conductivity, and Ions. Israel Program for Sci, Transl., Jerusalem, 1970.

Israel, H., Atmospheric Electricity, vol. II, Isr. Program for Sci. Transl., Jerusalem, 1973.
Kasemir, H. W., Measurement of the air-earth current density, in Proc. Conf. Atmos. Electricity, Geophys. Res. Pap., 42, 91-95, Air Force Cambridge Res., Cent., Bedford, Mass., 1955.

Kasemir, H. W. and L. H. Ruhnke, Antenna problems of measurement of the air-Earth current, in Recent Advances in Atmospheric Electricity, edited by L. G. Smith, pp. 137-147, Pergamon, New York, 1959.

Latha, R., Diurnal variation of surface electric field at a tropical station in different seasons: a study of plausible influences, Earth Planets Space, 55, 677-685, 2003.

Marcz, F., G. Satori, and B. Zieger, Variations in Schumann resonances and their relation to atmospheric electricity parameters at Nagycenk station, Ann. Geophys., 15, 1604-1614, 1997.

Mareev, E. A. and Anisimov, Global electric circuit as an open dissipative system, Proc. 12th Int. Conf. On atmospheric electricity, Versailles, vol. 2, pp 781-784, 2003.

Marshall, T. C., W. D. Rust, M. Stolzenburg, W. P. Roeder, and P. R. Krehbiel, A study of enhanced fair-weather electric fields occurring soon after sunrise, J. Geophys. Res., 104, 24,455-24,469, 1999.

Muir, M. S., The ionosphere as the source of the atmospheric electric sunrise effect, J. Atmos. Terr. Phys., 37, 553-559, 1975.

Muir, M. S., The potential gradient sunrise effect in atmospheric electricity, J. Atmos. Terr. Phys., 39, 229-233, 1977.

Panneerselvam, C., K. U. Nair, K. Jeeva, C. Selvaraj, S. Gurubaran, and R. Rajaram, A comparative study of atmospheric Maxwell current and electric field from a low latitude station Tirunelveli, Earth Planets Space, 55, 697-703, 2003.

Parkinson, W. C. and O. W. Torreson, The diurnal variation of the electric potential of the atmosphere over the oceans, UGGI Bull., 8, 340-341, 1931.

Prospero, J. M., Aerosol particles, in Global Tropospheric Chemistry: A plan for Action, Natl. Res. Counc., Natl. Acad. Press, Washington D.C., 1984.

Reiter, R., Fields, Currents and Aerosols in the Lower Troposphere, Division of Atmospheric Sciences, National Science Foundation, Washington D. C., publ. Amerind Publishing Co. Pvt. Ltd., New Delhi, 1985.

Reiter, R., Phenomena in Atmospheric and Environmental Electricity, Elsevier, 541 pp., New York, 1992.

Roble, R. G., On solar-terrestrial relationships in atmospheric electricity, J. Geophys. Res., 90, 6000-6012, 1985.

Ruhnke, L., H., Area averaging of atmospheric electric currents, J. Geomagn. Geoelectr., 21, 453-462, 1969.

Rycroft, M. J., S. Israelsson, and C. Price, The global atmospheric electric circuit, solar activity and climate change, J. Atmos. Solar-Terr. Phys., 62, 1563-1576, 2000.

Serbu, G. P. and E. M. Trent, A study of the use of atmospheric electric measurements in fog forecasting, Trans. Am. Geophys. UN, 39, 1034, 1958.

Smirnov, V. V., Ionization in the troposphere, Gidrometeoizdat, StPetersbourg, pp. 312, 1992.

Sorokin, A. E., S. V. Anisimov, and E. A., Mareev, Horizontal long-wire antenna as a fog electrical properties analyzer, Proc. of Conference on Fog and Fog Collection. St. John's Canada, pp. 473-476, 2001.

Tammet, H., S. Israelsson, E. Knudsen, and T. J. Tuomi, Effective area of a horizontal long-wire antenna collecting the atmospheric electric vertical current, J. Geophys. Res., 101, 29,671-29,677, 1996.

Whipple, F. j. W. and E. L. Scrase, Point discharge in the electric field of the earth, Met. Off. Geophys. Mem., London, 68, 20, 1936.

C. Panneerselvam (e-mail: panneer_iig@rediffmail.com), K. U. Nair, C. Selvaraj, K. Jeeva, C. P. Anil Kumar, and S. Gurubaran 